\title{
Распространенность хронической обструктивной болезни легких в Иркутской области
}

ГОУ ДПО "Иркутский государственный институт усовершенствования врачей"

\section{Yu.N.Krasnova, E.V.Grimailova, A.A.Dzizinsky, B.A.Cherniak Prevalence of chronic obstructive pulmonary disease in Irkutsk region}

\begin{abstract}
Summary
The aim was to investigate the prevalence of COPD in adults of urban and rural regions.

This was a cross-sectional epidemiological survey involved 1280 persons living at the Kachugski rural region and 1820 ones living at an urban (Bratsk) region; all of them were older than 18 yrs. We used a standardized questionnaire of respiratory symptoms (ECSC). Lung function tests were performed in all the participants; functional criteria of COPD were based on post-bronchodilating $\mathrm{FEV}_{1}<80 \%$ pred. and $/$ or $\mathrm{FEV}_{1} / \mathrm{FVC}<70 \%$. Prevalence of COPD in the population over 18 years of age was $6.6 \%$ in the rural region (14.6\% for males and $1.8 \%$ for females) and $3.1 \%$ in the urban region (4.7 and $1.6 \%$ correspondingly). The prevalence of COPD increased with aging: $10.1 \%$ in the town and $22.6 \%$ in the rural region for the males of 50 to 69 yrs old

Conclusion: the high prevalence of COPD in general population and low diagnosis of this disease were found particularly among males over 50 yrs of age.
\end{abstract}

\section{Резюме}

Цель исследования: изучить распространенность ХОБЛ среди городского и сельского населения Иркутской области.

Материалы и методы: проведено одномоментное, двухэтапное, выборочное эпидемиологическое исследование (cross-sectional study) среди 1280 человек, проживающих в сельском Качугском районе и 1820 в городе Братске, в возрасте старше 18 лет. Исследуемые были опрошены с помощью опросника для выявления респираторных симптомов (ЕCSC) и всем выполнялась спирометрия. Функциональными критериями ХОБЛ считали постбронходилататорные ОФВ $<80$ \% от должных величин и $/$ или ОФВ 1 ФЖЕЛ < $70 \%$.

Результаты: распространенность ХОБЛ среди лиц старше 18 лет в сельском районе составила 6,6 \% (среди мужчин - 14,6 \%, среди женщин - 1,8 \%), в городе $3,1 \%$ (4,7 и 1,6 \% соответственно). Распространенность ХОБЛ неуклонно увеличивается с возрастом. В возрастной категории 50-69 лет у 10,1\% мужчин в городе и у 22,6\% в сельском районе диагностирована ХОБЛ.

Заключение: выявлена высокая распространенность ХОБЛ, особенно среди мужчин старше 50 лет и гиподиагностика данного заболевания.

В настоящее время хроническая обструктивная болезнь легких (ХОБЛ) приобретает все большее медико-социальное значение, т. к. характеризуется высокой инвалидизацией и смертностью больных. В структуре причин смертности в возрастной группе старше 45 лет ХОБЛ занимает 4-е место. Существовавшая до недавнего времени нозологическая неопределенность и отсутствие единых критериев диагностики делали невозможным сравнение показателей распространенности и тяжести течения ХОБЛ в разных странах. Так, в мире, при оценке заболеваемости на 1000 представителей каждого пола, распространенность ХОБЛ в 1990 г. составляла 9,34 среди мужчин и 7,33 среди женщин, в Китае (1998) - 4,2 среди мужчин и 1,8 - среди женщин, в Великобритании (2000) - 17 среди мужчин и 14 среди женщин [1]. В США, по данным 1995 г., на 1000 курящих представителей каждого пола, ХОБЛ была диагностирована у 136 женщин и 142 мужчин [1].

Принятие единых для большинства стран диагностических критериев позволило проводить сравнительный анализ распространенности ХОБЛ в различных регионах мира. В 2005 г. были опубликованы результаты эпидемиологического исследования, проведенного в Корее среди 9243 лиц старше 18 лет. ХОБЛ выявлена у 7,8 \% населения старше 18 лет, у $10,9 \%$ мужчин и 4,9\% женщин, наибольшая $(17,2 \%)$ заболеваемость была отмечена среди лиц старше 45 лет, составившая 25,8 \% среди мужчин и 9,6\% среди женщин [2].

По данным Министерства здравоохранения и социального развития России, в стране насчитывается около 1 млн больных ХОБЛ. По мнению главного терапевта России академика А.Г.Чучалина, фактическое количество больных в нашей стране может превышать 11 млн [3], т. е. только каждый одиннадцатый пациент с ХОБЛ попадает в статистическую отчетность. Это связано с тем, что заболевание, как правило, не распознается на ранних стадиях. Официальные данные по распространенности заболеваний оцениваются по показателям, предоставляемыми лечебными учреждениями, т. е. в статистику за определенный период включаются лишь обратившиеся за медицинской помощью, или состоящие на диспансерном учете. Таким образом, официальные данные свидетельствуют в основном о распространенности клинически значимых, преимущественно тяжелых форм ХОБЛ. Достоверных данных об 
истинной распространенности ХОБЛ России до сих пор нет.

В Иркутской области мы провели одномоментное двухэтапное выборочное эпидемиологическое исследование для выявления ХОБЛ среди городского (г. Братск) и сельского (Качугский район) взрослого населения. По официальным данным, Братск на протяжении многих лет включен в список городов России с наиболее значительным загрязнением воздуха. Так, среднегодовые концентрации бензапирена, зарегистрированные в Братске, составляют 5,0 ПДК, а в отдельные месяцы - до 10 ПДК, формальдегида $-6,3$ ПДК, сероуглерода - 4,4 ПДК. В воздухе повышены концентрации оксида углерода, диоксида азота, растворимых твердых фторидов, фтористого водорода, метилмеркаптана и др. На территории Качугского района отсутствуют промышленные предприятия, и он относится к категории районов с экологически благополучной ситуацией.

На первом этапе в сформированной методом случайных чисел репрезентативной выборке численностью 1820 человек в возрасте старше 18 лет в Братске и 1280 - в Качугском районе, в условиях поквартирных обходов был осуществлен анкетный скрининг с помощью стандартизированных вопросников для выявления респираторных симптомов Европейского Общества Угля и Стали $(E C S C, 1987)$. Всем исследуемым, независимо от наличия или отсутствия респираторных симптомов, было проведено исследование функции внешнего дыхания с оценкой ОФВ 1 и соотношения ОФВ 1 / ФЖЕЛ. Пациентам с ОФВ 1 ФЖЕЛ $<70 \%$ и / или ОФВ $1 \leq 80 \%$ от должных величин был выполнен бронхомоторный тест с 400 мкг фенотерола гидробромида.

На втором этапе всем пациентам с респираторными симптомами и признаками бронхиальной обструкции (постбронходилатационный ОФВ 1 < $80 \%$ и / или ОФВ 1 / ФЖЕЛ < 70 \%) проводили КЛиническое обследование для верификации диагноза ХОБЛ и исключения других бронхообструктивных заболеваний и вторичного бронхообструктивного синдрома.

Информационно-аналитическую базу данных по результатам исследования формировали, используя пакет компьютерных программ Excel. При математической и статистической обработке результатов применялся пакет компьютерных программ Statistica 6,0. При сравнении выборочных показателей использовали непараметрические критерии: критерий $\chi^{2}$ и

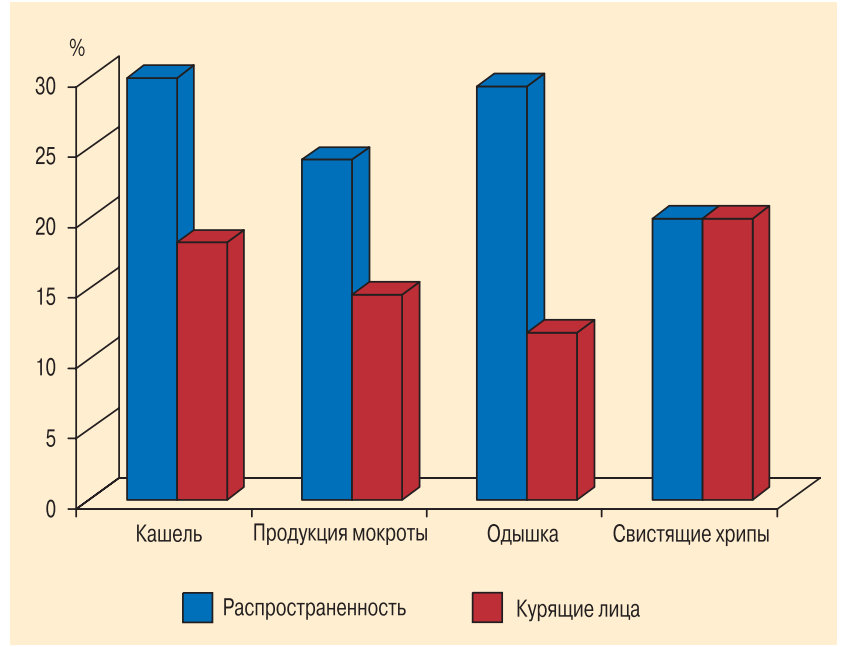

Рис.1. Распространенность респираторных симптомов

критерий Манна-Уитни. Различия считали достоверными при $p<0,05$.

Результаты анкетирования показали, что респираторные симптомы, такие как хронический кашель, отделение мокроты, свистящие хрипы и одышка носят распространенный характер: жалобы на кашель и одышку предъявлял каждый 3-й опрошенный. Причем $61,2 \%$ населения с хроническим кашлем и $100 \%-$ с эпизодически возникающими свистящими хрипами - курильщики (рис. 1).

Распространенность ХОБЛ среди городского населения составила $3,1 \%$, среди сельского $-6,6 \%$. Достоверно более часто, в 14,6\% случаев, ХОБЛ выявляли среди мужчин Качугского района, тогда как среди мужского населения Братска ХОБЛ диагностировали в $4,7 \%$ случаев $(p<0,01)$. Среди женщин в Братске ХОБЛ была подтверждена в 1,6 \% случаев и в 1,8 \% - в районе. Таким образом, было отмечено отчетливое, как в городе, так и в сельском районе, преобладание среди больных ХОБЛ мужчин. Соотношение мужчин и женщин с выявленной ХОБЛ в городе составило 2,9 / 1, в сельском районе $-8,1$ / 1 .

Распространенность ХОБЛ увеличивается с возрастом: в возрастной группе от 50 до 69 лет им страдают $10,1 \%$ мужчин в городе и $22,6 \%$ - в сельской местности. Практически у каждого второго мужчины в возрасте старше 70 лет, проживающего в сельской местности, была диагностирована ХОБЛ (табл. 1).

Большая распространенность ХОБЛ в сельском районе может быть обусловлена значимым вкладом

Таблица 1

Распространенность ХОБЛ среди городского и сельского населения

\begin{tabular}{|c|c|c|c|c|c|c|}
\hline \multirow{3}{*}{$\begin{array}{c}\text { Возраст, } \\
\text { годы }\end{array}$} & \multicolumn{6}{|c|}{ Распространенность ХОБЛ, \% } \\
\hline & \multicolumn{3}{|c|}{ среди городского населения } & \multicolumn{3}{|c|}{ среди сельского населения } \\
\hline & всего & мужчины & женщины & всего & мужчины & женщины \\
\hline $18-29$ & 0 & 0 & 0 & 0 & 0 & 0 \\
\hline $30-49$ & 1,5 & 2,3 & 0,6 & 2,5 & 5,4 & 0,9 \\
\hline $50-69$ & 5,3 & 10,1 & 2,3 & 9,5 & 22,6 & 2,3 \\
\hline$>70$ & 10,6 & 26,3 & 4,8 & 20,6 & 45,3 & 4.9 \\
\hline
\end{tabular}




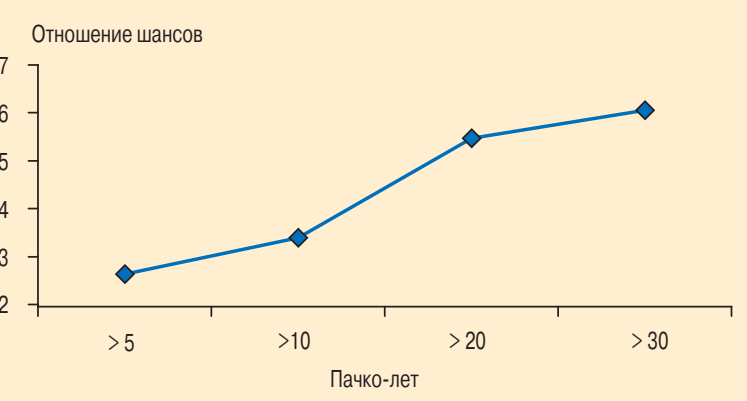

Рис.2. Зависимость показателя пачко-лет и отношение шансов ХОБЛ

курения в его развитие. При сравнительной оценке обращает на себя внимание достоверно большая распространенность курения среди мужчин старшей возрастной группы в сельском районе. Так, среди мужчин в возрасте старше 70 лет в сельском районе курит $35,9 \%$, в городе $-21,1 \%$ ( $p<0,05)$ (табл. 2). Показатель пачко-лет у мужчин в сельской местности также достоверно выше, чем в городе, и составляет 24,2 $\pm 17,7$ и 18,1 $\pm 14,4$ соответственно $(p<0,05)$. Среди женщин этот показатель не отличался и составил в среднем 9,5.

При оценке вероятности развития ХОБЛ у курящих следует отметить линейную зависимость между интегральным показателем пачко-лет и отношением шансов (ОШ) (рис. 2).

По нашим данным, курильщиками или экс-курильщиками были 75,8 \% больных ХОБЛ в городе и $88,2 \%$ - в сельском районе. Показатель пачко-лет также был выше среди больных ХОБЛ в районе, по сравнению с городом, составляя $38,6 \pm 21,2$ и $32,5 \pm$ 19,3 соответственно $(p>0,05)$.

С помощью критерия Хотеллинга (Т2) был проведен анализ 14 параметров курения среди больных ХОБЛ в городе и в сельском районе. Оценивали длительность, интенсивность и регулярность курения, начало курения, степень никотиновой зависимости, индекс курящего человека и др. Критерий Хотеллинга - многомерный аналог t-критерия Стъюдента, использующийся для проверки гипотезы о равенстве 2 векторов средних, отражающий различия групп по совокупности средних величин всех изучаемых признаков. При сравнении совокупности параметров курения среди городских и сельских жителей, больных ХОБЛ, критерий Хотеллинга оказался равен 82,0 $(p<0,00001)$, что подтвердило значимость различий.
В структуре ХОБЛ в общей популяции преобладают первая и вторая стадии заболевания: в сельском районе на них приходится 72,1\% всех случаев ХОБЛ, тогда как на третью и четвертую - лишь 27,9 \%. Основную массу больных ХОБЛ, не включенных в официальную статистику, составляют пациенты с легкой и среднетяжелой ХОБЛ. У 62 \% выявленных в Братске больных ранее диагностировали хронический бронхит, однако диагноз ХОБЛ в $100 \%$ случаев был подтвержден впервые в рамках проведенного исследования. Лишь 20 \% пациентов с ХОБЛ регулярно использовали бронхолитики. Специфическая терапия не проводилась у $93 \%$ больных легкой, $83,3 \%$ - среднетяжелой, 83,3\% - тяжелой и у $67 \%$ - крайне тяжелой ХОБЛ.

Для выяснения причин гиподиагностики ХОБЛ и неадекватности терапии мы проанализировали знания врачей о современных методах диагностики и лечения ХОБЛ. Было опрошено 240 терапевтов, 184 из них работали в поликлиниках и 56 - в общетерапевтических стационарах. Только $72 \%$ из них считали, что основным методом диагностики ХОБЛ является исследование ФВД. Лишь $4 \%$ терапевтов смогли назвать функциональные критерии ХОБЛ и проанализировать протокол спирометрии. Более $50 \%$ врачей не знали, как и для чего проводится бронхомоторный тест с бронхолитиком. Бронхолитики, как основную группу медикаментозных препаратов, использующихся в лечении ХОБЛ, назвали $61 \%$ врачей, но среди бронхолитиков $60 \%$ отдали предпочтение теофиллинам, а холинолитики и $\beta_{2}$-агонисты упомянули $40 \%$ врачей. Таким образом, одной из причин гиподиагностики и неадекватности терапии у больных ХОБЛ, является незнание терапевтами современных принципов диагностики и лечения ХОБЛ, что особенно актуально в свете принятия Национальной приоритетной программы в современном здравоохранении, главным содержанием которой является укрепление первичного звена медико-санитарной помощи.

Первоочередными задачами, направленными на уменьшение инвалидизации и снижение смертности от ХОБЛ, в настоящее время являются профилактика и раннее выявление максимального количества случаев заболевания, для чего необходимы четкие скоординированные действия различных медицинских учреждений. Для подразделений профилактической медицины - это активное внедрение разработанных

Таблица 2

Частота курения в различных возрастных группах

\begin{tabular}{c|c|c|c|c|c|c|}
\multirow{3}{*}{$\begin{array}{c}\text { Возраст, } \\
\text { годы }\end{array}$} & \multicolumn{9}{|c}{ Частота курения, \% } \\
\cline { 2 - 7 } & \multicolumn{3}{|c|}{ среди городского населения } & \multicolumn{4}{c}{ среди сельского населения } \\
\cline { 2 - 7 } & всего & мужчины & женщины & всего & мужчины & женщины \\
$18-29$ & 59,7 & 67 & 45,8 & 64,8 & 76,2 & 54,7 \\
$30-49$ & 50,8 & 65,8 & 32,3 & 42,3 & 69,8 & 26,4 \\
$50-69$ & 24,5 & 50,7 & 8,3 & 28,5 & 61 & 10,8 \\
$>70$ & 6,3 & 21,1 & 0,9 & 18,8 & 35,9 & 7,9 \\
\hline
\end{tabular}


и апробированных антиникотиновых программ, направленных на лечение никотиновой зависимости и предотвращение распространения курения. На основании данных о факторах риска заболевания, врачам первичного звена рекомендуется формирование групп пациентов с высоким риском развития ХОБЛ и ежегодное мониторирование у них ФВД.

В настоящее время разработана Федеральная программа по диагностике и лечению ХОБЛ и, с одной стороны, обязательно соблюдение Программы пульмонологами, а с другой - необходимо ознакомление с основными положениями этой программы врачей общей практики, профпатологов, администраторов и организаторов здравоохранения.

\section{Выводы}

1. В Иркутской области заболеваемость ХОБЛ особенно высока среди мужчин старше 50 лет. Среди сельского населения, независимо от возраста, заболеваемость ХОБЛ достоверно выше, чем в городе, что связано с повышенным риском развития ХОБЛ у активных курильщиков;
2. Гиподиагностика и неадекватность терапии при ХОБЛ связана с недоценкой пациентами значимости клинических симптомов, с устаревшими представлениями врачей первичного звена о функциональных критериях ХОБЛ и возможностях терапии, а также с недостаточно активным выявлением больных в группах лиц с повышенным риском развития ХОБЛ.

\section{Литература}

1. Global Initiative for Chronic Obstructive Lung Disease $(G O L D)$. Global strategy for diagnosis, management, and prevention of chronic obstructive pulmonary disease. NHLBI / WHO workshop report. 2005.

2. Kim D.S., Kim Y.S., Jung K.S. et al. Prevalence of chronic obstructive pulmonary disease in Korea: A populationbased spirometry survey. Am. J. Respir. Crit. Care Med. 2005; 172 (7): 842-847.

3. Чучалин А.Г. (ред.) Клинические рекомендации. Пульмонология. М.: ГЭОТАР-Медиа; 2005. 171-172.

Поступила 11.01.2006 () Коллектив авторов, 2006 удк 616.24-036.12-036.21 